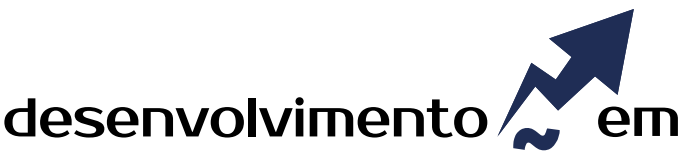 QUESTÃO
}

\section{Rede de Colaboração da Agricultura Familiar no Município de Porto Velho-RO}

\author{
http://dx.doi.org/10.21527/2237-6453.2020.52.335-354 \\ Recebido em: 2/7/2019 \\ Aceito em: $28 / 2 / 2020$ \\ Eliane Alves Silva, ${ }^{1}$ Sérgio Nogueira do Nascimento, ${ }^{2}$
Mariluce Paes de Souza, ${ }^{3}$ Eugenio Avila Pedrozo ${ }^{4}$
}

\begin{abstract}
RESUMO
Há necessidade de se desenvolver uma economia alternativa em que a exploração pode ser evitada, com novas perspectivas de ocupação produtiva, reforçando trajetórias de inclusão social. O objetivo deste artigo, portanto, é analisar o processo de relações, práticas e translações da formação de uma rede da agricultura familiar no município de Porto Velho-RO, sob a ótica da Teoria Ator-Rede. Sua relevância consiste em provocar reflexões sobre quem são os atores dessa rede, como influenciam e são influenciados e quais os resultados dessa interação. Este artigo caracteriza-se por ser uma pesquisa analítica, de natureza qualitativa e direcionada por um estudo de caso. Utilizou-se da Teoria Ator-Rede (TAR), a qual traz contribuições importantes por se tratar de uma abordagem que propõe uma modificação em relação ao que se entende por "social". Conclui-se que a rede foi construída em torno de três pilares: ideologia campesina, mercado e setor público. A ideologia campesina compreende a organização dos agricultores, Sindicato dos Trabalhadores Rurais do Brasil, Confederação Nacional dos Trabalhadores na Agricultura (Contag) e União de Cooperativas da Agricultura Familiar e Economia Solidária (Unicafes). O setor público é representado pelas Secretarias Municipais Semed, Semagric, juntamente com as escolas municipais, pela Conab e Emater. 0 mercado compreende o Sebrae e os consumidores de produtos agroecológicos. Verificou-se que o setor público junto com a ideologia camponesa, são responsáveis pela inclusão de agricultores mais vulneráveis à rede, e que, à medida que os agricultores vão se consolidando, migram do papel de camponeses para o de empreendedores.
\end{abstract}

Palavras-chave: Desenvolvimento sustentável. Agricultura familiar. Políticas públicas. Teoria Ator-Rede.

\section{COLLABORATION NETWORK OF FAMILY AGRICULTURE IN PORTO VELHO-RO}

\section{ABSTRACT}

There is a need to develop an alternative economy where exploitation can be avoided, new prospects for productive occupation and reinforce trajectories of social inclusion. Therefore, the objective of this paper is to analyze the process of relationships, practices and translations of the formation of a family farming network in the city of Porto Velho-RO, from the perspective of the Actor-Network Theory. Its relevance is to provoke reflections on who are the actors of this network, how they influence and are influenced and what are the results of this interaction. This article is characterized by being an analytical research, qualitative and directed by a case study. It was used the Actor-Network Theory (ANT), which brings important contributions, because it is an approach that proposes a modification in relation to what is meant by "social". It was concluded that the network was built around three pillars: peasant ideology, market and public sector. The peasant ideology includes the farmers 'organization, the Rural Workers' Union of Brazil, the National Confederation of Agricultural Workers (Contag) and the Union of Family Farming and Solidarity Economy Cooperatives (Unicafes). The public sector is represented by the municipal departments Semed, Semagric together with the municipal schools, by Conab and Emater. The market comprises Sebrae and consumers of agroecological products. It has been found that the public sector along with peasant ideology are responsible for including more vulnerable farmers into the network, and the extent to farmers consolidating, they migrate from peasant to entrepreneurial.

Keywords: Sustainable development. Family farming. Public policy. Actor-Network Theory.

\footnotetext{
${ }^{1}$ Mestranda em Administração pela Universidade Federal de Rondônia (Unir). Lattes:http://lattes.cnpq.br/1834027792929773. https://orcid.org/0000-0002-6958-1101. elianealvesil@yahoo.com.br

${ }^{2}$ Mestrando em Administração pela Universidade Federal de Rondônia (Unir). http://lattes.cnpq.br/9323426926094595. https://orcid.org/ 0000-0003-2084-780X.adm_sergionogueira@yahoo.com

${ }^{3}$ Doutora em Ciências Socioambientais pela Universidade Federal do Pará (Ufpa). Professora da Universidade Federal de Rondônia (Unir). http://lattes.cnpq.br/6930021151410221. https://orcid.org/0000-0002-4202-0769.mariluce@unir.br

${ }^{4}$ Doutor em Genie Industrielle pelo Institut National Polytechnique de Lorraine (INPL), França. Professor da Universidade Federal do Rio Grande do Sul (UFRGS). http://lattes.cnpq.br/0734321648126694. https://orcid.org/0000-0002-4751-707X. eugenio.pedrozo@ufrgs.br
} 
A demanda agrícola para alimentar a população continuará a crescer nos próximos anos, colocando pressão adicional sobre a terra disponível e outros recursos naturais. As práticas atuais estão minando a ecologia do sistema alimentar global por meio do uso excessivo e dos efeitos da poluição agrícola, aumentando, assim, a degradação, reduzindo a capacidade do ecossistema para gerar rendimentos sustentáveis. A prática agrícola sustentável pode ser a resposta para uma maior segurança alimentar, proteção ambiental e redução da pobreza (FAO, 2011; IFAD, 2013).

Vale ressaltar que os agricultores familiares gerenciam mais de $80 \%$ das $500 \mathrm{mi}$ Ihões de pequenas propriedades estimadas no mundo e fornecem mais de $80 \%$ dos alimentos consumidos em grande parte do mundo em desenvolvimento, contribuindo significativamente para a redução da pobreza e a segurança alimentar. A fragmentação crescente das propriedades da terra, juntamente com a redução do apoio ao investimento e a marginalização de pequenas propriedades agrícolas na política econômica e de desenvolvimento, ameaça essa contribuição, deixando muitos pequenos proprietários vulneráveis (FAO, 2011; IFAD, 2013).

Com sua experiência coletiva e conhecimento íntimo das condições locais, os agricultores familiares detêm muitas das soluções práticas que podem ajudar a colocar a agricultura em uma base mais sustentável e equitativa. Para fazer isso, eles precisam de ajuda para superar as falhas do mercado e outros desincentivos ao uso sustentável da terra, incluindo a posse insegura desta, altos custos de transação e fraco apoio institucional (FAO, 2011; IFAD, 2013; LÉLÉ, 1991; SACHS, 1992).

Os desafios da agricultura familiar para atender a demanda por alimentos saudáveis e em quantidade são muitos, a começar pela renda. Sem uma renda que garanta vida digna, as famílias continuarão abandonando o meio rural. A insuficiência de investimentos em infraestrutura produtiva, de beneficiamento, armazenamento, transportes e preços remuneradores, bem como o acesso a políticas públicas de cunho social, como saúde, educação, previdência e transporte públicos, são fatores decisivos para a permanência das pessoas no campo.

Há necessidade de se desenvolver uma economia alternativa, em que a exploração pode ser evitada, com novas perspectivas de ocupação produtiva, e reforçar trajetórias de inclusão social; um cenário alternativo e desejado, que contemple um "novo modelo de desenvolvimento" para a Amazônia, com interação sistêmica entre atores e instituições para alcançar objetivos de crescimento, inovação, competitividade, equidade e sustentabilidade. Com base nessa contextualização, a presente pesquisa tem por objetivo analisar o processo de relações, práticas e translações da formação de uma rede da agricultura familiar no município de Porto Velho-RO, sob a ótica da Teoria Ator-Rede. Sob este prisma, a política agrícola, baseada no agricultor familiar, deverá prever a solução das questões técnicas surgidas em âmbito da produção propriamente dita, da circulação, da distribuição, do consumo e da produção, prevendo, igualmente, a organização dessa população, visando à sua efetiva integração social produtiva (CASTRO, 1996).

Fica claro que para que ocorra essas mudanças deve-se investigar o aspecto social. Neste sentido, mostra-se pertinente buscar teorias que possam contribuir para o avanço dos estudos na área. Sendo assim, este estudo utiliza-se da Teoria Ator-Rede (TAR), que foca nas relações práticas entre as partes para análise da rede de colabora- 
ção da agricultura familiar no município de Porto Velho. Esta teoria traz contribuições importantes para os estudos na área, por se tratar de uma abordagem que propõe uma modificação em relação ao que se entende por "social", avançando-se para uma sociologia de associações, quando humanos e não humanos têm poder de agência. Para tanto, utilizou-se como base os trabalhos de Latour, Callon e Law, precursores e principais estudiosos no campo desta teoria (TONELLI, 2016; ALCADIPANI; TURETA, 2009; PECI; ALCADIPANI, 2006; ARENDT, 2008; CAVALCANTI; ALCADIPANI, 2013).

A presente pesquisa trata-se de um estudo de caso intrínseco e analítico. Foram feitas entrevistas em profundidade com quatro cooperados na Cooperativa de Produtos e Serviços Agrícolas de Agricultores Familiares do Estado de Rondônia (Coopafaro), uma produtora filiada a uma Associação no setor chacareiro, dois técnicos da Empresa de Assistência Técnica e Extensão Rural de Rondônia (Emater-RO), um representante da Secretaria Municipal de Agricultura e Abastecimento (Semagric) e um nutricionista da equipe da Divisão de Alimentação Escolar (Diale), alocada na Secretaria de Educação do município de Porto Velho (Semed).

Este artigo, além dessa introdução, está organizado com referencial teórico, apresentando tópicos da Teoria Ator-Rede, e principais políticas públicas para agricultura familiar. Em seguida, aborda-se a metodologia; logo após os resultados e as discussões; e, por fim, apresenta-se as conclusões e observações finais e as referências bibliográficas consultadas.

\section{REFERENCIAL TEÓRICO}

A TAR propõe uma nova sociologia de associações, incluindo outros atores na análise, promovendo fundamentação teórica para discussão de dados empíricos; logo se faz necessário apresentar as políticas públicas, que mobilizam diversas organizações envolvidas com preservação e expansão de renda do pequeno produtor, assim como instituições comprometidas com a diminuição da pobreza e a garantia da segurança alimentar. Para compreender a linha de raciocínio proposta neste estudo e a complexidade que envolve o tema, buscou-se entender a teoria do Ator-Rede e conhecer algumas das principais políticas direcionadas à agricultura familiar.

\section{Teoria Ator-Rede}

A Teoria Ator-Rede (TAR) teve início nas obras de Latour (1997), Callon (1986) e Law (1992). Segundo Alcadipani e Tureta (2009), a TAR diferencia-se das demais teorias organizacionais, tendo como principais características: 1) ser ontologicamente relativista, pois considera que o mundo pode ser organizado de muitas formas diferentes, não devendo ser assumido a priori um modelo de análise que defina o que e quais são os elementos a serem observados no campo, considerando que a realidade é algo construído por meio de práticas e relações; 2) ser empiricamente realista, exigindo a realização de estudos empíricos, pois considera possível analisar redes de atores que desempenham práticas e processos, mesmo que, em um primeiro momento, seja difícil saber o que/quem faz as coisas acontecerem ou as pessoas agirem. Sendo assim, há uma maior ênfase nos processos do que numa visão estática e objetiva da realidade; 3 ) 
incluir elementos não humanos como participantes da organização, devendo-se, portanto, também considerá-los na análise organizacional; e 4) colocar o processo organizado como foco fundamental da análise (CAMPOS; PALMA, 2017).

Assim, a reflexão aqui propiciada alicerçou-se nos principais conceitos advindos dos trabalhos destes autores, que embasam a Teoria Ator Rede: 1) social e coletivo; 2) simetria; 3) rede; 4) translação; 5) o pressuposto metodológico de seguir os atores. A TAR não assume, a priori, uma supremacia dos humanos em relação aos não humanos. Os humanos não são nem mais nem menos importantes no plano analítico. Deste modo, uma vez que não humanos são parte ativa de várias vidas e que somente é possível falar de atores dentro de redes heterogêneas compostas por humanos e não humanos, torna-se difícil estudar as relações sociais e técnicas sem considerá-los (ALCADIPANI; TURETA, 2009; CAMPOS; PALMA, 2017).

Para a TAR, social é o nome de um movimento, um deslocamento, uma transformação, uma translação, um registro. Integra tipos de relações que não são sociais em si mesmas e trazem os não humanos ao centro do debate sociológico, postulando que os mesmos são dotados de agência e que, consequentemente, são atores de plenos direitos. Segundo Latour (2012), os não humanos precisam ser atores e não meras projeções simbólicas. A continuidade de um curso de ação não assume, a princípio, uma supremacia dos humanos em relação aos não humanos. Os humanos não são nem mais nem menos importantes no plano analítico. Deste modo, somente é possível falar de atores dentro de redes heterogêneas compostas por humanos e não humanos, tornando-se difícil analisar as relações sociais e técnicas sem considerá-los (ALCADIPANI; TURETA, 2009).

Esse princípio de análise baseia-se na ideia de simetria. Para eles, a ideia de simetria aplica-se ao verdadeiro e ao falso e esforça-se por reelaborar a construção da natureza e da sociedade. Segundo Alcadipani e Tureta (2009), a simetria é um dos mais importantes princípios da TAR. Refere-se à ideia de que a mesma explicação deve ser empregada para todos os elementos que compõem uma rede heterogênea, sejam eles humanos ou não humanos, grupos sociais ou forças naturais, pois não é possível dissociá-los. "Ambos participam conjuntamente da rede heterogênea, não podendo ser separados em qualquer situação empírica. Desta forma, tanto os humanos quanto os não-humanos não existem sozinhos. Há diferentes híbridos em que seria difícil demarcar fronteiras" (ALCADIPANI; TURETA, 2009).

Outro conceito importante é o de actantes. Este não é a fonte de uma ação, mas o alvo móvel de uma enorme quantidade de entidades que convergem para ele. Segundo Latour, (2012), "empregar a palavra 'ator' significa que jamais fica claro quem ou o que está atuando quando as pessoas atuam". Complementam Alcadipani e Tureta (2009) que atores são entidades que agem, que formam redes, que provocam mudanças no conjunto de elementos e conceitos habitualmente utilizados para descrever as coisas. São redes compostas por elementos heterogêneos (pessoas, máquinas, textos, dinheiro, etc.) contingencialmente conectados.

As redes, por sua vez, significam uma série de transformações. São compostas por um conjunto de elementos heterogêneos que foram ligados uns aos outros por um período de tempo, não possuindo uma formação e uma composição fixa, estável e definida, podendo ser alteradas a qualquer momento. São duráveis não apenas por causa 
da ligação entre seus elementos e porque cada entidade constitui uma rede em si, de modo que qualquer mudança nas entidades de uma rede-de-atores gera transformações na própria rede (ALCADIPANI; TURETA, 2009).

A translação também é um conceito fundamental para a TAR. Segundo o entendimento de Latour (2001), translação "refere-se a todos os deslocamentos por entre outros atores cuja mediação é indispensável à ocorrência de qualquer ação". Assim, de acordo com o autor, ao invés do contexto e conteúdo, a translação refere-se ao trabalho graças ao qual atores modificam, deslocam e transladam seus vários e contraditórios interesses (LATOUR, 2001).

Nessa mesma linha, Moraes (2004) esclarece que é fundamental distinguir translação de interação, uma vez que a primeira, muitas vezes, parece remeter a um tipo de relação linear que vincula humanos entre si. Assim, a translação envolve, simultaneamente, um desvio e uma articulação de elementos díspares e heterogêneos, uma vez que esta "refere-se à hibridização, mestiçagem, multiplicidade de conexões, sendo sustentada por uma ontologia definida por sua hibridização" (MORAES, 2004). O processo de translação é, desse modo, fundamental para a compreensão das redes de "actantes", uma vez que é este movimento, a translação, que molda a lógica das redes: ao mesmo tempo em que algo se mantém, algo se modifica (TURETTA; ALCADIPANI, 2009).

O primeiro momento - a problematização - ocorre quando emergem os desafios a serem enfrentados pelos atores bem como os elementos sociais e naturais do enredo tomam forma. Nesta etapa, são revelados os interesses e obstáculos que devem ser ultrapassados, assim como as alianças que devem ser construídas entre os grupos de atores. Em um segundo momento, denominado "interessamento", um dos atores, por meio de um conjunto de ações, tenta impor seus interesses aos demais, cujas identidades procuram controlar por meio de estratégias de enfrentamento do problema. No recrutamento, terceiro momento, há uma busca por aliados e definição de papéis, marcada por um jogo de resultados incertos, uma vez que os dispositivos utilizados no interessamento não levam necessariamente à formação de alianças (CAMPOS; PALMA, 2017).

O quarto momento do processo reside na mobilização e nas dissidências dos atores em situações que expõem publicamente os representantes dos grupos. Callon (1986) enfatiza que tais etapas não somente descrevem um processo que se dá por meio da combinação de elementos naturais e sociais, tratados de forma simétrica, uma vez que vai além, mostrando como um grupo de poucos elementos - ou um único elemento - obtém o direito de expressar e representar os muitos atores silenciosos que o mobilizaram (CAMPOS; PALMA, 2017).

Como principal contribuição metodológica, destaca-se o fundamento de "seguir os atores", não os definindo a priori. Isso possibilita encontrar novas relações, atores e redes, abrindo caminhos para novos estudos. Além disso, afastar-se do antropocentrismo também é um passo importante a ser dado. A TAR possibilita tal afastamento ao propor uma nova sociologia de associações, incluindo outros atores na análise, que foram excluídos pela sociologia do social, criticada por Latour. 
A TAR é uma teoria muito rica no sentido de promover fundamentação teórica para discussão de dados empíricos; logo se faz necessário apresentar alguns atores responsáveis pela simetria dessa rede de colaboração da agricultura familiar.

\section{Agricultura familiar e as políticas públicas}

A agricultura familiar passou a contar com um leque de políticas públicas específicas para preservação e expansão da renda, tais como o crédito rural, assistência técnica seguro-safra e programas de compras governamentais do PAA e PNAE. Não obstante, alguns autores (MALUF, 2004; SCHERMER, 2015; SCHWARTZMAN et al., 2017) alertam que ao mesmo tempo em que a importância econômica da atividade agropecuária avança, aumentam os riscos quanto à sustentabilidade do modelo de agricultura adotado. Afirmam ainda que, em contraposição a esta realidade, os sistemas orgânicos e de base agroecológica contribuem positivamente para o equacionamento da agenda ambiental global (produção e conservação), para o alivio à pobreza e para a garantia da segurança alimentar (ONU, 2019).

O Programa de Aquisição de Alimentos (PAA) possui duas finalidades básicas: promover o acesso à alimentação e incentivar a agricultura familiar. Para o alcance desses dois objetivos, o programa compra alimentos produzidos pela agricultura familiar, com dispensa de licitação, e os destina às pessoas em situação de insegurança alimentar e nutricional e àquelas atendidas pela rede socioassistencial e pelos equipamentos públicos de alimentação e nutrição. Também contribui para a constituição de estoques públicos de alimentos produzidos por agricultores familiares e para a formação de estoques pelas organizações da agricultura familiar. Para o alcance de todos os objetivos a que se propõe, o PAA é desenvolvido em cinco modalidades diferentes: Doação Simultânea, Compra Direta, Formação de Estoques, PAA Leite e Compra Institucional. Seu orçamento é composto por recursos do Ministério do Desenvolvimento Social e Combate à Fome (MDS) e do Ministério do Desenvolvimento Agrário (MDA) (BRASIL, 2012b, 2013).

O PAA foi instituído pelo artigo 19 da Lei no 10.696, de 2 de julho de 2003, no âmbito do Programa Fome Zero. Esta Lei foi alterada pela Lei no 12.512, de 14 de outubro de 2011. O PAA foi ainda regulamentado por diversos decretos; o que está em vigência é o Decreto no 7.775, de 4 de julho de 2012. É operacionalizado por Estados, Distrito Federal e municípios e, ainda, pela Companhia Nacional de Abastecimento (Conab), empresa pública, vinculada ao Ministério da Agricultura, Pecuária e Abastecimento (Mapa), responsável por gerir as políticas agrícolas e de abastecimento. Para execução do Programa, a Conab firma Termo de Cooperação com o MDS e com o MDA (BRASIL, 2012b, 2013).

Por sua intersetorialidade e abrangência, o PAA é um Programa que conta com ampla participação da sociedade civil. Era instância de controle do PAA o Conselho de Segurança Alimentar e Nutricional (Consea), porém, no início da gestão do governo de Jair Bolsonaro, em 2019, foi extinto (ZOCCHIO, 2019). Logo, na hipótese de inexistência desse, os Conselhos de Desenvolvimento Rural Sustentável ou os Conselhos de Assistência Social poderão ser responsáveis pelo acompanhamento da execução do PAA (BRASIL, 2012b, 2013). 
O Programa Nacional de Alimentação Escolar (PNAE) é uma política que visa a garantir merenda escolar aos estudantes da rede pública. Sua origem remete-se à medida tomada pelo governo pela instituição, em 1940, do salário mínimo e a criação do Serviço de Alimentação da Previdência Social (Saps), destinado à melhoria dos hábitos alimentares do trabalhador. Em 1945 criou-se a Comissão Nacional de Alimentação (CNA) e, em 31 de março de 1955, foi assinado o Decreto $n^{\circ}$ 37.106, que instituiu a Campanha de Merenda Escolar (CME), subordinada ao Ministério da Educação, sendo considerado o marco inicial do programa (FNDE; PNAE, 2018a). Em 1976, o programa já era financiado pelo Ministério da Educação e gerenciado pela Campanha Nacional de Alimentação Escolar como parte do II Programa Nacional de Alimentação e Nutrição (Pronan), e, em 1979, o programa passou a denominar-se Programa Nacional de Alimentação Escolar (FNDE, 2018b).

Com a publicação da Lei 11.947, em 16 de junho de 2009, exige-se que, do total do repasse financeiro do PNAE, no mínimo $30 \%$ seja utilizado na aquisição de gêneros alimentícios diretamente da agricultura familiar. A Lei também dispensa a obrigatoriedade de licitação para aquisições deste grupo de fornecedores, devendo o município efetuar o processo de chamada pública na qual a escolha pelo fornecedor não é determinada pelo menor preço.

Em relação ao Programa Nacional de Fortalecimento da Agricultura Familiar (Pronaf), entende-se que estimula a geração de renda e melhora o uso da mão de obra familiar, por meio do financiamento de atividades e serviços rurais agropecuários e não agropecuários, desenvolvidos em estabelecimento rural ou em áreas comunitárias próximas. São seus beneficiários os agricultores e produtores rurais que compõem as unidades familiares de produção rural e que comprovem seu enquadramento mediante apresentação da "Declaração de Aptidão ao Pronaf (DAP)" ativa (BRASIL, 2019).

O uso da expressão agricultura familiar, sobretudo nas políticas públicas, denota um conteúdo ideológico. A agricultura familiar, porém, pode abranger tanto o campesinato quanto a agricultura empresarial (VILAS-BOAS, 2018). Ao promover a generalização de grupos tão heterogêneos, seu emprego mascara singularidades e diferenças, minimizando a importância dada a características como o modo de vida camponês, sua relação com a terra e o meio ambiente. Neste contexto, Silva (2007) e Navarro (2010) advogam que o critério governamental de divisão da agricultura em familiar e patronal é problemático, pois utiliza como parâmetros apenas a questão do trabalho e da direção familiar.

Ao se exemplificar essas políticas públicas, a questão da agricultura familiar é mais bem compreendida. As políticas para este setor estão associadas à cultura "camponesa", embasadas na noção de reprodução econômica da pequena agricultura familiar, sendo associadas à geração de uma renda suficiente para manter a família e usar os recursos naturais de forma sustentável. Em contraste, porém, com o atual governo, que possui uma visão neoliberal, elas tendem a sofrer modificações ou serem extinguidas, pois acredita-se que uma ideologia se sobrepõe a outra. Por isso, a análise da rede de colaboração da agricultura familiar se faz necessária, questionando a divergência ou a convergência destes pontos de vista. No próximo tópico será apresentado procedimentos metodológicos para coleta de dados. 


\section{Metodologia da Pesquisa}

Trata-se de um caso intrínseco (STAKE, 2000), orientado para a singularidade, pois buscou, a partir daquilo que emergiu da prática, compreender situações, responder questões e resolver um quebra-cabeça (MERRIAM, 2002). Segundo Yin (2001), existem múltiplas fontes de evidências; no presente caso foram documentos, entrevistas e observações. É considerado um estudo analítico, pois buscou-se ouvir os participantes e desenvolver um entendimento baseado nas ideias deles (MERRIAM, 2002), além de detalhar o relato sobre um fenômeno a fim de ilustrar sua complexidade, considerando os diversos atores envolvidos (GODOY, 2010; STAKE, 2000).

As entrevistas ocorreram entre abril e maio de 2019. Foram entrevistados quatro cooperados na Cooperativa de Produtos e Serviços Agrícolas de Agricultores Familiares do Estado de Rondônia (Coopafaro), uma produtora filiada a uma associação no Setor Chacareiro, dois técnicos da Empresa de Assistência Técnica e Extensão Rural de Rondônia (Emater-RO), um representante da Secretaria Municipal de Agricultura e Abastecimento (Semagric) e uma nutricionista da equipe da Divisão de Alimentação Escolar (Diale), alocada na Secretaria de Educação do município de Porto Velho (Semed). Ao todo foram nove entrevistas em profundidade. O perfil de cada entrevistado segue descritos no Quadro 1.

\section{Quadro 1 - Perfil dos entrevistados}

\begin{tabular}{|l|l|l|}
\hline Entrevistado & Instituição & Característica \\
\hline Entrevistado A & Coopafaro & $\begin{array}{l}\text { Agricultor, filiado à Confederação Nacional dos Trabalhadores } \\
\text { na Agricultura (Contag), sendo um dos mais antigos filiados nos } \\
\text { programas PAA e PNAE no município. }\end{array}$ \\
\hline Entrevistado B & Coopafaro & $\begin{array}{l}\text { Agricultor que participou da fundação da cooperativa e atua na } \\
\text { comissão logística da mesma. }\end{array}$ \\
\hline Entrevistada C & Setor Chacareiro & Assentada em terra considerada zona de litígio no município. \\
\hline Entrevistado D & Coopafaro & $\begin{array}{l}\text { Agricultor cooperado que, além de fornecer produtos para a } \\
\text { cooperativa, atua em feiras livres. }\end{array}$ \\
\hline Entrevistado E & Emater & $\begin{array}{l}\text { Técnica que realiza cadastramento e acompanha os agricultores no } \\
\text { PAA. }\end{array}$ \\
\hline Entrevistado F & Coopafaro & $\begin{array}{l}\text { Agricultor cooperado que possui uma agroindústria produtora de } \\
\text { polpa de frutas. }\end{array}$ \\
\hline Entrevistado G & Emater & $\begin{array}{l}\text { Técnico que realiza cadastramento e acompanha os agricultores no } \\
\text { PNAE. }\end{array}$ \\
\hline Entrevistada H & Diale & Nutricionista que atua na operacionalização do PNAE. \\
\hline Entrevistado I & Semagric & Técnica que atua com os produtores rurais e o PNAE. \\
\hline
\end{tabular}

Fonte: Dados da pesquisa.

Efetuou-se análise de documentos internos fornecidos pelos entrevistados, como o Relatório circunstanciado das atividades Diale; Decreto municipal 15.417 de 30 de agosto de 2018, no qual constam as atribuições de todos os membros da Diale; Tabela de preço a ser praticada pelos agricultores cadastrados no programa de agricultura familiar, emitida pela Semagric; Modelo de projeto de venda de gêneros alimentícios da agricultura familiar para alimentação escolar, fornecido pela Emater; e, por fim, o Estatuto da Coopafaro. 
Os documentos serviram para a familiarização com o fenômeno de modo a identificar e acompanhar as principais translações em seus deslocamentos e composições. Houve complementação das informações por meio de dados secundários provenientes da página eletrônica da Prefeitura do município; documentos externos, como informações prestadas pelo Fundo Nacional do Desenvolvimento da Educação (FNDE); página eletrônica da Emater-RO; página eletrônica do IBGE; página eletrônica do Ministério do Desenvolvimento Social (MDS); e, por fim, as leis federais 8.666/93, 10.696/03, 11.947/09, 12.512/11 e decreto 7.775/12.

As observações foram na modalidade observador não participante, embora o propósito fosse conhecido, e a identidade de pesquisador era clara para todos os envolvidos, posto que este somente observava os informantes (SAUNDERS; LEWIS; THORNHILL, 2012). Foram feitas observações em três momentos: no atendimento e desenvolvimento das atividades diárias dos funcionários e cooperados da Coopafaro; na propriedade rural da produtora filiada a uma Associação no setor chacareiro; e no atendimento e desenvolvimento das atividades diárias dos funcionários da Emater. Essas observações tiveram em média duração de 1 hora.

A análise dos dados ocorreu por meio da identificação e acompanhamento das translações ocorridas (CALLON, 1986) no processo de instrumentação das políticas públicas investigadas. Para isso, os documentos, anotações das observações de campo e entrevistas foram organizados em quatro divisões de acordo com as translações: problematização, interessamento, recrutamento e mobilização dos programas voltados para agricultura familiar no município de Porto Velho. Por fim, foi realizada uma triangulação que permitiu identificar como as participações, as relações e interações dos atores se deram no processo de instrumentação de tais políticas públicas no município.

\section{RESULTADOS E DISCUSSÕES}

Os limites nas relações com os atores podem ser considerados o principal desafio a ser vencido para o processo de relações, práticas e translações da formação de uma rede da agricultura familiar no município de Porto Velho-RO. Para Latour (1997), "os atores sabem o que fazem e nós temos que aprender com eles não apenas o que eles fazem, mas também, como e por que fazem determinadas coisas" para assim reprogramar as relações das quais fazem parte e buscar novas formas de integração dos actantes. A rede de colaboração da agricultura familiar compreende os agricultores familiares; cooperativas, políticas públicas, instituições públicas, sendo, neste caso, analisadas as municipais e federais; entidades filantrópicas; escolas municipais; Serviço Brasileiro de Apoio às Micro e Pequenas Empresas (Sebrae); e consumidores de produtos agroecológicos.

A rede foi construída em torno de três pilares: ideologia camponesa, mercado e setor público. A ideologia camponesa compreende a organização dos agricultores, Sindicato dos Trabalhadores Rurais do Brasil, Confederação Nacional dos Trabalhadores na Agricultura (Contag) e União de Cooperativas da Agricultura Familiar e Economia Solidária (Unicafes). O setor público é representado pelas Secretarias Municipais Semed e Semagric, juntamente com as escolas municipais, Conab e Emater. O mercado compreende o Sebrae e os consumidores de produtos agroecológicos. Estes atores juntaram-se por meio das políticas públicas voltadas para a agricultura familiar. 
Entende-se como ideologia camponesa, o sistema de ideias voltado à coletividade, direcionando suas ações às necessidades do grupo, não às ambições individuais neste caso o maior patrimônio transmitido pelo camponês aos seus herdeiros não é a terra, mas seu modo de vida. (VILAS-BOAS, 2018). Para a Contag, a agricultura familiar é a melhor forma de promover a inclusão e o desenvolvimento com sustentabilidade do campo, garantindo produção de alimentos com qualidade e em quantidade para atendimento à demanda da população. Enquanto a Unicafes entende que as cooperativas solidárias se configuram como um instrumento importante para se alterar o ambiente social e econômico de todas as regiões do Brasil (ZANCO; CORBARI; ALVES, 2018). Assim sendo, essas instituições representam o pilar ideologia camponesa.

No que diz respeito ao mercado, o agricultor converte-se em empreendedor, buscando vínculo com o mercado para obter lucro. O principal representante desse pilar é o SEBRAE, que entra nessa rede para incentivar a integração entre os diferentes segmentos da cadeia produtiva e de consumo de produtos orgânicos e a regionalização da produção e comércio desses produtos.

Enquanto ao setor público, encontra-se fortemente atrelado às políticas públicas para a agricultura familiar. Essas, por sua vez, são consideradas o ator-rede congregando uma associação que mobiliza diversas organizações envolvidas com preservação expansão de renda do pequeno produtor assim como instituições comprometidas com a diminuição da pobreza e garantia da segurança alimentar, como por exemplo, Emater, Conab e Semed, Semagric e Contag, que modificam, deslocam e transladam interesses. Considerando isso, num primeiro momento de translação identificado, surgiu a problemática que reuniu os atores conforme as declarações do entrevistado:

A maior concentração de produtores de Porto Velho tá dentro da área da agricultura familiar [...] O PNAE nosso aqui nasceu do Programa Fome Zero; o primeiro Programa Fome Zero no Brasil, foi feito aqui em Rondônia por nós. Então o primeiro PAA, muito benfeito, nós fomos para Brasília representar Rondônia, mostrar para o presidente Lula o programa do PAA que deu certo em Rondônia e aí deslanchou para o Brasil todo... Isso surgiu depois do PAA, que era bem dinâmico; ele passou a ter o Sabor do Campo, via Semed, ... adequando o PAA à alimentação escolar das escolas municipais. [...] Já com briga muito do Sindicato dos trabalhadores Rurais do Brasil, lá em Brasília, através da Contag e dos sindicatos, nós conseguimos os $30 \%$ do recurso do PNAE para compra da agricultura familiar (Entrevistado A).

Esse trecho da entrevista mostra a relação do PAA com o PNAE. O PAA foi o que abriu a possibilidade ou acumulou a experiência para incluir a produção do agricultor rural na merenda escolar. Segundo Schwartzman et al. (2017), antes da publicação da Medida Provisória no 544 e da Lei no 11.947 de 2009, existiam algumas experiências isoladas e pontuais de compras diretas para o PNAE em alguns municípios, mas que só eram possíveis graças aos esforços de gestores interessados na questão do desenvolvimento local. Foi somente com a instituição da modalidade de compras denominada chamada pública, a partir da publicação da Lei no 11.947, que as compras locais se tornaram realmente possíveis. Com a lei 11.947 a problemática evoluiu para um segundo momento, o interessamento. 
A Semed passou a habilitar as propostas que continham todos os documentos exigidos no edital e preços de venda dos produtos compatíveis com o mercado. Depois realiza, no mínimo, três pesquisas no mercado local ou regional. Para produtos orgânicos ou agroecológicos, caso não tenha como fazer pesquisa de preço, é possível o acréscimo em até $30 \%$ do valor do produto em relação ao preço dos produtos convencionais. O comprador, no caso a escola, e o fornecedor assinam o contrato que estabelece o cronograma de entrega dos produtos, a data de pagamento aos agricultores familiares e todas as demais cláusulas de compra e venda. O início da entrega dos produtos deve atender ao cronograma previsto e os pagamentos são realizados diretamente aos agricultores ou suas organizações. (SEMED, 2019; MDS, 2012,2013).

Os fornecedores podem participar do PAA e/ou PNAE individualmente ou por meio de suas cooperativas ou outras organizações formalmente constituídas como pessoa jurídica de direito privado. Para participar dos Programas individualmente, os fornecedores devem possuir a Declaração de Aptidão ao Pronaf (DAP), instrumento que qualifica a família como da agricultura familiar. Já as organizações de agricultores, devem deter a Declaração de Aptidão ao Pronaf (DAP) Especial Pessoa Jurídica (SEMED; 2019, MDS, 2012,2013).

Para entrar nos programas, os produtores também precisam de um projeto de venda de gêneros alimentícios da agricultura familiar obtida junto a Emater-RO. Os técnicos da Emater visitam as propriedades semanalmente, tentando conciliar a demanda de produtos procurados pela Semed e Semagric com a produção da agricultura familiar, com isso é feito um planejamento sazonal para atender cada programa. A Emater em Porto Velho é composta por 10 técnicos, sendo 7 técnicos atuando diretamente no suporte das pequenas propriedades. Somente pelo PAA, até maio de 2019, atendiam 115 famílias (EMATER-RO, 2019b).

Cabe também à Emater a capacitação dos produtores, fornecendo treinamentos de boas práticas na manipulação e comercialização de alimentos, assim como no manejo de sua produção. Para isso possuem um programa voltado ações práticas de agroecologia, que atende a diversos sistemas das unidades de produção familiar, se voltando para a área vegetal com maior destaque para a produção de hortaliças e sistemas agroflorestais com base no café. Entretanto, sua aplicação tem sido encontrada na pecuária de gado, aves e lavoura branca. A agroecologia fortalece circuitos locais e regionais e também redes de comercialização, valorizando a biodiversidade e a produção orgânica e agroecológica de alimentos, além de incentivar hábitos alimentares saudáveis e estimular o associativismo (EMATER-RO, 2019a). Conforme observado na fala de um dos entrevistados na instituição:

[...] A Emater incentiva e orienta muitos produtores quanto à embalagem, porque essa produção que vai ser entregue nas escolas, vai ser entregue para as famílias carentes; são pessoas, né, que vão tá alimentando, então o produto tem que ser de boa qualidade, o produto não pode ter agrotóxico, é uma coisa que tem que ser orgânico de verdade, porque são alunos que vão usar [...] Esse mês passado a Emater fez até uma capacitação... vou até te mostrar... nós fizemos uma cartilha de boas práticas, fabricação e manipulação de alimentos para os produtores feirantes (Entrevistada E). 
$\mathrm{Na}$ observação feita na Emater verificou-se como o produtor entra no PNAE. Primeiro o produtor faz uma visita para adquirir sua Declaração de aptidão do Pronaf (DAP), depois o técnico vai até sua propriedade inspecionar questões estruturais para o plantio e verificar se a família possui os requisitos para receber a DAP. Com a DAP em mãos, o agricultor senta com o técnico para preencher o projeto de venda de gêneros alimentícios. O técnico tem acesso aos cardápios que as nutricionistas emitem e ele possui uma noção de quais produtos ele pode recomendar para que o agricultor consiga plantar e atender a próxima alteração do cardápio. A princípio quando o produtor está iniciando, são recomendados condimentos e hortaliças. Depois de preencher os produtos que o agricultor pode atender, consulta-se a tabela de preços emitida pela Semagric, para calcular o valor que pode vender. O máximo permitido para o programa é 20 mil Reais, mas geralmente o produtor individual, não atinge esse valor. Com o projeto pronto, ele é encaminhado para a Semed para se qualificar para a próxima chamada pública.

Conforme modelo do termo de compromisso do agricultor, cedido pela Emater, podem fornecer produtos ao Programa de Aquisição de Alimentos (PAA), os agricultores familiares e os demais beneficiários que se enquadrem nas disposições da Lei no 11.326, de 24 de julho de 2006. Os alimentos adquiridos pelo PAA serão destinados a ações de promoção de segurança alimentar e nutricional ou à formação de estoques. Logo podem ser doados a pessoas e famílias em situação de insegurança alimentar e nutricional. O limite individual de venda do Agricultor Familiar deverá respeitar o valor máximo de até $\mathrm{R} \$ \mathbf{6 . 5 0 0 , 0 0}$ (Seis mil e quinhentos reais), por DAP por ano civil. E a definição dos produtos, volumes e preços dos alimentos adquiridos dos agricultores familiares serão pactuados com a coordenação local do Programa.

Todas essas ações da Semed e da Emater, caracterizam o recrutamento dos agentes, constituindo o terceiro momento dessa rede de colaboração. Essas duas instituições são os actantes que modificam a realidade dos outros atores atuando na execução e manutenção das políticas públicas. O quarto momento, que seria a mobilização dos atores é observado nos próximos fragmentos das entrevistas:

No início tudo é muito difícil, né, quando a gente começou aí, muito tempo atrás, era bem pequenininho a nossa estrutura, nóis entregava numa moto, numa carretinha, e a gente se programava para fazer a entrega em dois dias e a nossa propriedade dá $80 \mathrm{~km}$ da cidade, então tinha uma grande dificuldade e todos os produtores vinha até a cidade para trazer os produtos deles, entendeu? Então com a dificuldade que a gente tinha para poder todo mundo se locomover a gente primeiro teve uma associação no Joana D'Arc, aonde criamos ali uma comissão que vinha fazer esse trabalho; não precisava todos os produtores vir [...] E aí depois a gente pegou e achou melhor criar uma cooperativa, aí nóis só foi crescendo e dentro da cooperativa a gente tem várias comissão para poder fazer a entrega, a parte da logística. E hoje nós estamos muito melhor; fazer entrega. nós temos pessoas diretamente, né, trabalhando; os outros na parte da entrega, a parte da logística [...] E hoje nós estamos muito melhor; nóis estamos hoje com caminhão baú; nóis temos um carro pequeno para fazer entrega, 11 pessoas diretamente, né, trabalhando [...] Começamos com 15 cooperados, né; hoje está aproximadamente 22 com DAP; nóis temos o total de 50 cooperado, 20 com DAP; nóis temos mais 15 que tão agora aderindo junto, então vamos agregar quase 70 pessoas [...] Mas nóis somos tam- 
bém associado na Unicafes de Ji-Paraná e aí a gente sempre faz curso; já tivemos em Foz do Iguaçu, me lembro que eu passei em Foz do Iguaçu; eles têm uma experiência muito muito, são os pioneiros de Rondônia (Entrevistado B).

O aspecto importante ressaltado pelo entrevistado foi a Unicafes (União de Cooperativas da Agricultura Familiar e Economia Solidária). Conforme Mance (2002) esse modo de organizar e praticar o cooperativismo fortalece o desenvolvimento sustentável e solidário, articulando iniciativas econômicas que ampliam as oportunidades de trabalho, de distribuição de renda, de produção de alimentos e melhoria de qualidade de vida. Suas diretrizes são bases orientadoras para ações dos diversos ramos cooperativos, e, são inseridas nas estratégias de ação das cooperativas associadas e das centrais, fundamentando a relação entre os ramos cooperativos e as diretrizes defendidas pelo Cooperativismo Solidário (UNICAFES, 2017; ZANCO; CORBARI; ALVES, 2018).

Outro exemplo de mobilização foi observado dentro da cooperativa, onde os produtores se reúnem diariamente. Primeiramente os funcionários do setor administrativo chegam, lançam as notas dos produtos que vão ser entregues, cadastram novos produtos (até o dia da entrevista eram 108), depois passam a lista das escolas que solicitaram produtos para os cooperados da comissão de entrega. No decorrer da manhã em que a observação foi feita os funcionários recebem os cooperados atendendo dúvidas de documentação, principalmente referente a DAP. Há alguns que já possuem, porém outros não, mas é explicado a eles que podem participar do PNAE utilizando a DAP da cooperativa. Vale ressaltar que a Coopafaro foi criada para atender o PNAE, grande parte da produção dos cooperados é destinada ao programa. Embora ocorra exceções, pois foi entrevistado um produtor rural que possuí uma agroindústria de polpa de frutas e emprega 10 pessoas em sua propriedade. Além de atender as políticas públicas voltadas para a alimentação, já consegue produzir excedente para ser vendido no comércio local.

[...] Eu não tinha documento ainda necessário para poder participar da venda direta da merenda escolar, né; eu tinha a documentação da polpa, mas não era as exigências, que não atendia as exigências da Semed [...] Então nós vendia mais era banana, melancia, frutas e verduras [...] Hoje eu atendo mais mercado, nós vendemos pra Semed, pra Seduc, e nós vendemos também para outro mercado aqui da região, padarias, lanchonetes, né, e nós vendemos, fornecemos também banana. Hoje nós também tamo mais estruturado; tem a cooperativa que dá o apoio pra gente também (Entrevistado F).

A cooperativa na busca pela expansão trabalha em parceria com o Sebrae, incentivando seus cooperados a se capacitarem e a buscar outras alternativas além dos programas. Isto é um exemplo de que as redes, como estados parciais de ordem, podem ser visualizadas como estruturas abertas a um constante fluxo de externalidades aonde ocorre uma permanente reconfiguração a partir da negociação dos atores (CALLON, 1986). As redes de atores colocam conjuntamente partes e peças do social, do técnico, do conceitual e do textual, traduzindo-as em materialidades heterogêneas que moldam umas às outras para produzir ordenações, uma vez que as "conexões transformam recursos esparsos numa teia que parece se estender por toda parte" (LATOUR, 2001). Elas processam-se naquilo que pode ser amarrado, no caso a busca por capacitação. Isso 
torna forte a capacidade da rede de gerar associações, numa cadeia em que as configurações são praticamente realizadas pelos atores que, ao transladar seus interesses, inserem outros atores.

A realidade dos produtores assentados em zona de litígio é diferente em relação à realidade dos cooperados:

Aqui no setor chacareiro quando eu cheguei para cá, eu fui sentada nessa pequena área aqui por uma presidente de Associação [...] Ela sentou aqui na época; eu não entendia que ser sentada assim na terra qui não era do Incra, que essa aqui dizem que era do [...] mas ele não pagou uma determinada taxa no Incra; teve terra, pedaços aqui que ele não tinha documento [...] a outra parte dele que é 800 hectares, 400 e pouco é hipotecada no banco. Uma terra já saiu o título. Já saiu a última martelada do juiz, o agricultor ganhou. Agora é essa que é o lote 2, essa aqui onde eu moro, é... um diz que ainda tá em Brasília, tá pra se resolver e por causa disso a Ceron na época, que hoje ela é Eletrobrás, nunca entrou porque diz que a terra tando em litígio não pode ter, ninguém pode ficar no claro, é isso quer dizer né. Não fizeram, aí a gente fez essa rede; ela é particular; cada um comprou transformador, entendeu? Pagamos caro por essa rede a aí hoje tamo tendo [...] Mas já ta tendo levantamento aqui para dentro, to vendo pessoal da empresa terceirizada fazendo levantamento para regularizar [...] Porque é bom ser regularzinho; você mora bem aqui e você não tem um comprovante de residência; o comprovante de residência que eu tenho aqui é o CAR, licenciamento ambiental, que nem todo mundo quer aceitar [...] eu quero ter meu comprovante de residência; provar onde eu moro é bom para mim (Entrevistada C).

Nessa parte da entrevista, a agricultora ressalta que a falta de comprovante de residência inviabiliza a aquisição de empréstimos para investir na propriedade. Neste caso, as políticas públicas precisam desempenhar um papel como alinhamento do ator para apoiar o processo de incorporação institucional, ajudando na construção ou modificação de redes de agricultores para estimular as iniciativas "botton-up" (OERLEMANS; ASSOULINE, 2004). Chayanov (1981) reforça o estímulo "de baixo para cima", afirmando que a agricultura camponesa produz valor de uso. Para o autor, o agricultor depende da preservação da terra para sua sobrevivência, posto que ela é o seu meio de produção. Os agricultores, portanto, conservam suas terras, almejando o lucro a largo prazo.

Eu entrei no PNAE através do programa da Emater que eu tenho os técnicos que me acompanha muitos anos. Há 10 anos atrás que eu vim ter técnico da Emater para me acompanha. Até então era só para o sustento da família, sabe porque não tinha, era só entregar em mercadinho aqui no Santana, que era uns poucos. A gente contava uns 3 mercadinho, aí daí eu conheci a (nutricionista da Semed) na reunião né. Falei com ela, e a escola que me deu foi a Padre Giovanni [...] continuei, e ela me deu três escolas na época. Mas aí eu adoeci com esse problema de câncer de mama; parei tudo; fiquei só com uma porque meu marido passava lá deixá nela minha frutinha. E aí eu fiquei boa, retornei à escola e peguei mais uma. [...] O PNAE me ajudou muito, entendeu? Eu adquiri irrigação para horta para trabalhar, entendeu? Quando eu adoeci, eu achei que eu ia morrer; vendi trator, um bocado de coisa de trabalhar na horta, a bicicleta cargueira que era para entregar aqui perto, né, a gente vendeu. Mas aí eu fiquei boa e com vontade de trabalhar [...] que eu tô de boa; então é assim; eu retornei pro trabalho ano passado; já diz setembro para dezembro, né. Não deu; assim que eu ganhar só deu para entrar no meu trabalho e ganhei pouco porque a terra é o centro do que tu ganha, né (Entrevistada C). 
Mais uma vez fica em evidência a dependência das políticas públicas, pois a produtora possui o PNAE como única fonte de renda e essa renda foi muito afetada no período em que estava doente. Percebe-se que a rede de atores é o poder das práticas implícitas no discurso dos domínios da vida cotidiana usado para articular o jogo social. As práticas discursivas articulam diferentes vozes para constituir uma materialidade estratégica, e o reconhecimento desse discurso revela como as ordenações se formam (FOUCAULT, 1995). Elas processam-se em circuitos discursivos para produzir regularidades de associação entre múltiplos atores, tornando-se centros temporários e situacionais de ordem. Conforme relato da agricultora, no setor chacareiro os moradores colaboram entre si, reunindo-se por meio de associações e, muitas vezes, praticando a "política da boa vizinhança":

Na época tinha carro; ajudei muita gente que não tinha. [...] tem um amigo aí que tinha um abacaxi lá na época e ele ia fechar um programa, mas não tinha dinheiro para o frete [...] fui buscar o abacaxi dele. É sem contar que quando eu ia levar um saco de macaxeira de uma colega. Eu sempre fiz isso aí, tem que ser, né, minha fiIha, porque a gente não ajudar como é que quer ser ajudado; eu não tenho muitas coisas; isso é tudo, é como que é a cooperação entre um e outro (Entrevistada C).

Conforme Vilas-Boas (2018), a expressão agricultura familiar nas políticas públicas denota um conteúdo ideológico. É valido ressaltar, no entanto, que a agricultura familiar pode abranger tanto o campesinato quanto a agricultura empresarial. Logo, essa generalização é problemática, pois utiliza como parâmetros apenas a questão do trabalho e da direção familiar. Essa má interpretação pode levar à extinção de programas, conforme a fala de um dos entrevistados:

Eu me recordo que quando era jovem, nos manter na propriedade somente com o dinheiro arrecadado e ganhar do próprio sítio era muito difícil, muito difícil, é nós plantávamos para subsistência também nessa época, mas sempre tínhamos que sair para fora para trabalhar, porque infelizmente o produto que você plantava, você não vendia, se vendia, você tinha que vender superbarato. Não pagava nem os custeios, não pagava a adubação que naquela época era pouco, mas fazíamos também, né. Então era tudo rudimentar, né, irrigação impensável; você não podia, porque era tudo caro, você não tinha investimento do governo em nada, o governo não te apoiava [...] O governo, já parou tudo, né, os projetos que estavam em andamento, eles foram pausados, eu acredito que o FNO que vinha para ajudar o produtor, o Pronaf, né, eles estão parados, só tem custeio; agora mesmo, essa notícia eu já verifiquei. Só tem custeio e assim eu acho, assim, se houver realmente esse movimento e acabarem o investimento da agricultura familiar [...] Quem sabe, será que vai haver novamente o êxodo rural? Novamente? O homem do campo vai vir para a cidade? Aí vai superpopular a metrópole e deixar o campo jogado ao léu, virar pasto, ou o grande latifundiário vai plantar soja, né, e aí, a agricultura básica que é o que alimenta, a melancia, a verdura, a banana, que vários produtores trazem pouquinho; a pouco garantindo a subsistência de sua família, vai deixar de existir? (Entrevistado D).

Vale ressaltar que o valor referente ao PAA do ano vigente, depositado no mês de junho, ainda não tinha sido repassado. É certo que durante uma transição de governos ocorra alguns ajustes, e atrasos devem ser compreendidos. Mediante a extinção do Conselho de Segurança Alimentar e Nutricional (Consea), o qual era a instância de controle do PAA, todavia, essa política se vê ameaçada. 
A abordagem do ator-rede possibilita vislumbrar a execução de políticas públicas pelo processo dinâmico que lhes constitui por meio da coocorrência de situações em uma ordem que é sempre contextual; um pressuposto pertinente para a gestão pública que deve operar num contexto múltiplo e mais complexo de forças na articulação de atores de âmbito governamental e não governamental e no seu comprometimento com metas coletivas. A formação de políticas públicas baseadas na descentralização e na participação social, exige padrões de flexibilidade que sejam facilitadores de novas relações sociais e políticas, de maneira a renovar a capacidade de governança pela pluralização da sociedade não apenas pelo seu controle sobre a ação pública, mas também pela sua própria ação estratégica e decisória dentro do espaço público. Como salienta Dowbor (2003), é um novo equilíbrio de "quem faz o que", reformulando as bases de regulação social em que o Estado passa a funcionar de forma diferente e precisa ser repensado, principalmente a partir das relações de poder.

Esse equilíbrio é ressaltado pela entrevistada da Diale, que afirma que os agricultores cooperados mais antigos no PNAE já conseguem atingir novos mercados, não dependendo apenas do programa. Conforme visto anteriormente, ainda existem agricultores fortemente dependentes, como no caso do Setor Chacareiro. A nutricionista defende a importância de cadastrar novos agricultores por meio da chamada pública. No trecho a seguir relembrou o trabalho que foi feito para se fazer a primeira chamada pública para atender a Lei 11.947 de 2009, em que $30 \%$ dos produtos adquiridos para a merenda escolar devem ser provenientes da agricultura familiar.

Os nossos agricultores já estão maiorzinhos, vamos dizer assim, querendo novos ares. Agora seria o resgate de novos agricultores. Agora a gente teria que fazer tudo que fizemos em 2010 de novo (Entrevistada H).

É certo que há uma conexão envolvendo diferentes atores na rede de colaboração da agricultura familiar, por isso deve-se atuar com os devidos cuidados nas políticas públicas, que são agentes de simetria. Ao se desestruturar um programa pode haver rompimentos nas relações, além de prejudicar o desenvolvimento sustentável, colocando a população em vulnerabilidade alimentar. Sobre os três pilares em que os relacinamentos se apoiam, verificou-se que o setor público, juntamente com a ideologia camponesa, é responsável pela inclusão de agricultores mais vulneráveis à ela. À medida que os agricultores vão se consolidando, passam a buscar novos mercados, migrando do papel de camponês para o de empreendedor.

Este estudo não quer cair no mérito de se discutir sobre as diferentes ideologias da agricultura familiar, porém a abrangência do conceito engloba a base campesina e a base empreendedora, aparentemente dois conceitos antagônicos, mas que interagem entre si. Ocorrem translações na rede envolvendo essas duas bases, e interpretar essa interação com base em um pilar pode desestruturá-la. Por isso, as políticas públicas para o agricultor familiar são necessárias; são agentes de simetria para o desenvolvimento sustentável.

\section{CONSIDERAÇÕES FINAIS}

É importante realizar novos estudos direcionados às políticas públicas que incentivam a produção agrícola familiar. A sociedade deve ter consciência do peso dessa produção, pois $80 \%$ de sua alimentação depende do pequeno agricultor, e qualquer deses- 
truturação nesses programas poderá causar efeitos irreversíveis. Tendo como objetivo compreender a rede de colaboração da agricultura familiar por meio da TAR, este estudo chegou à conclusão que a conexão foi construída em torno de três pilares: ideologia campesina, mercado e setor público. Identificou-se os atores-rede, os agentes de simetria, como sendo as políticas públicas PAA, PNAE e Pronaf. O pilar da ideologia campesina compreende a organização dos agricultores, Sindicato dos Trabalhadores Rurais do Brasil, Confederação Nacional dos Trabalhadores na Agricultura (Contag) e União de Cooperativas da Agricultura Familiar e Economia Solidária (Unicafes). O mercado compreende o Sebrae e os consumidores de produtos agroecológicos, enquanto o pilar do setor público é representado pelas Secretarias Municipais Semed e Semagric, juntamente com as escolas municipais, Conab e Emater.

A TAR propiciou analisar a execução das políticas voltadas aos agricultores familiares a partir das ações e das relações dos atores oriundos e atuantes em diferentes escalas de interesse. A ação foi assim inscrita pela translação desses atores que, em suas associações, geraram estratégias para produzir uma ordem sempre parcialmente estabilizada na contínua construção do grupo. A presente teoria facilitou acompanhar essa trajetória da produção de fatos por entre conteúdos e contextos (LATOUR, 2001) das redes de atores, e pode se constituir num recurso para análise da formação e gestão de políticas públicas dentro de um caráter múltiplo de ordenação.

Vale ressaltar o conteúdo ideológico da expressão agricultura familiar, que pode abranger tanto o campesinato quanto a agricultura empresarial, embora essa generalização possa acarretar sérios problemas no gerenciamento das políticas públicas, confrontando um ponto de vista neoliberal com o modo de vida camponês. Cabe, para se analisar esse contexto, a reflexão de Edgar Morin (2002, p. 89), em que "é preciso substituir um pensamento que une e separa por um pensamento que distingue e une".

Falta, no entanto, trazer ainda mais próximo os sujeitos, pois quando se pensa na continuação da trajetória da rede verifica-se que essa possui vários ramos com suas particularidades. Embora os programas têm pontos em comum e se entrelaçam em alguns momentos, seria interessante analisar as conexões formadas pelos programas em específico. Se este estudo se repetir numa esfera estadual, abrangendo secretarias e escolas estaduais do mesmo município, já se teriam outros resultados, pois a organização dos atores é diferente. É interessante, portanto, ampliar esta pesquisa para outras regiões, levando em consideração a administração municipal e estadual.

\section{REFERÊNCIAS}

ARENDT, R. J. J. Maneiras de pesquisar no cotidiano: contribuição da teoria do ator-rede. Revista Psicologia \& Sociedade, n. 20, p. 7-11, 2008. Disponível em: http://www.scielo.br/pdf/psoc/v20nspe/v20nspea03.pdf. Acesso em: 10 jun. 2019.

ALCADIPANI, R.; TURETA, C. Teoria ator-rede e análise organizacional; contribuições e possibilidades de pesquisa no Brasil. Organizações \& Sociedade, v. 16, n. 51, 2009. Disponível em: http://www.redalyc.org/ pdf/4006/400638319004.pdf. Acesso em: 10 jun. 2019.

BRASIL. Banco Central do Brasil (Bacen). Programa Nacional de Fortalecimento da Agricultura Familiar Pronaf, 2019. Disponível em: https://www.bcb.gov.br/acessoinformacao/legado?url=https:\%2F\%2Fwww. bcb.gov.br\%2Fpre\%2Fbc_atende\%2Fport\%2FPRONAF.asp. Acesso em: 10 jun. 2019.

BRASIL. Decreto $n^{\circ} 7.775$ de 4 de julho de 2012. Diário Oficial [da] República Federativa do Brasil, Brasília, DF. 2012a. Disponível em: http://www.planalto.gov.br/ccivil_03/_Ato2011-2014/2012/Decreto/D7775. htm. Acesso em: 27 abr. 2019. 
BRASIL. Lei Federal no 8.666 de 21 de junho de 1993. Diário Oficial [da] República Federativa do Brasil, Brasília, DF. 1993. Disponível em: planalto.gov.br/ccivil_03/LEIS/L8666cons.htm. Acesso em: 16 abr. 2019. BRASIL. Lei no 10.696, de 2 de julho de 2003. Diário Oficial [da] República Federativa do Brasil, Brasília, DF. 2003. Disponível em: http://www.planalto.gov.br/ccivil_03/LEIS/2003/L10.696.htm. Acesso em: 28 abr. 2019.

BRASIL. Lei Federal no 11.326 de 24 de julho de 2006. Diário Oficial [da] República Federativa do Brasil, Brasília, DF. 2006. Disponível em: https://www2.camara.leg.br/legin/fed/lei/2006/lei-11326-24-julho-2006-544830-normaatualizada-pl.html. Acesso em: 16 abr. 2019

BRASIL. Lei Federal no 11.326 de 24 de julho de 2006. Diário Oficial [da] República Federativa do Brasil, Brasília, DF. 2006. Disponível em: https://www2.camara.leg.br/legin/fed/lei/2006/lei-11326-24-julho-2006-544830-normaatualizada-pl.html. Acesso em: 16 abr. 2019.

BRASIL. Lei Federal no 11.947 de 16 de junho de 2009. Diário Oficial [da] República Federativa do Brasil, Brasília, DF, 2009. Disponível em: http://www.planalto.gov.br/ccivil_03/_Ato2007-2010/2009/Lei/ L11947.htm. Acesso em: 26 abr. 2019.

BRASIL. Lei Federal no 12.512 de 14 de outubro de 2011. Diário Oficial [da] República Federativa do Brasil, Brasília, DF, 2011. Disponível em: http://www.planalto.gov.br/ccivil_03/_Ato2011-2014/2011/Lei/ L12512.htm. Acesso em: 26 abr. 2019.

BRASIL. Ministério do Desenvolvimento Social (MDS). Cartilha Programa de Aquisição de alimentos da Agricultura Familiar, Brasília, 2012b. Disponível em: http://www.mda.gov.br/sitemda/sites/sitemda/files/ user_arquivos_64/CARTILHA_PAA_FINAL.pdf. Acesso em: 10 jun. 2019.

BRASIL. Ministério do Desenvolvimento Social (MDS). PAA 10 anos de Aquisição de alimentos, Brasília, 2013. Disponível em: https://fpabramo.org.br/acervosocial/estante/paa-10-anos-de-aquisicao-de-alimentos/. Acesso em: 10 jun. 2019.

CALLON, M. Some elements of a sociology of translation: domestication of the scallops and the fishermen of St Brieuc Bay. The Sociological Review, v. 32, n. S1, p. 196-233, 1986. Disponível em: https://onlinelibrary.wiley.com/doi/abs/10.1111/j.1467-954X.1984.tb00113.x. Acesso em: 10 jun. 2019.

CAMPOS, S. A. P.; PALMA, L. C. Contribuições da teoria Ator-Rede para o estudo da sustentabilidade. RMS-Revista Metropolitana de Sustentabilidade, v. 7, n. 1, p. 47-67, 2017. Disponível em: http://www.revistaseletronicas.fmu.br/index.php/rms/article/view/1070/pdf. Acesso em: 10 jun. 2019.

CASTRO, A. T. A política pública no setor agrícola em Rondônia: proposta de reformulação face ao fenômeno migratório. 1996. Dissertação (Mestrado) - Escola Brasileira de Administração Pública, Fundação Getúlio Vargas, Rio de Janeiro, RJ, Brasil, 1996. Disponível em: http://bdtd.ibict.br/vufind/Record/FGV_ 50cae6ba439f8353c1af53e1a7865b48/Details. Acesso em: 10 jun. 2019.

CAVALCANTI, M. F. R.; ALCADIPANI, R. Organizações como processos e Teoria Ator-Rede: a contribuição de John Law para os estudos organizacionais. Cadernos EBAPE. BR, v. 11, n. 4, p. 556-568, 2013. Disponível em: http://www.spell.org.br/documentos/ver/18848/organizacoes-como-processos-e-teoria-ator-rede--a-contribuicao-de-john-law-para-os-estudos-organizacionais. Acesso em: 10 jun. 2019.

CHAYANOV, A. Sobre a teoria dos sistemas econômicos não capitalistas. In: SILVA, J. G. da; STOLCKE, V. (org.). A questão agrária: Weber, Engels, Lenin, Kautsky, Chayanov, Stalin. São Paulo: Brasiliense, 1981. p. 133-163.

DOWBOR, L. A reprodução social. V. III: descentralização e participação: as novas tendências. Petrópolis: Vozes, 2003.

FAO. Food and Agriculture Organization. The State of the World's Land and Water Resources for Food and Agriculture (SOLAW) - Managing systems at risk. Rome: Food and Agriculture Organization of the United Nations; London: Earthscan, 2011. Disponível em: http://www.fao.org/3/a-i1688e.pdf. Acesso em: 10 jun. 2019.

FOUCAULT, M. A arqueologia do saber. 4. ed. Rio de Janeiro: Forense Universitária, 1995.

FNDE. Fundo Nacional de Desenvolvimento da Educação (Brasil); PNAE. Programa Nacional de Alimentação Escolar. Dados da agricultura familiar: aquisições da agricultura familiar no período de 2011 a 2016. Brasília/DF, 2018a. Disponível em: https://www.fnde.gov.br/programas/pnae/pnae-consultas/pnae-dados-da-agricultura-familiar. Acesso em: 26 dez. 2018.

FNDE. Fundo Nacional de Desenvolvimento da Educação (Brasil). Sobre o PNAE. Disponível em: https:// www.fnde.gov.br/index.php/programas/pnae/pnae-sobre-o-programa/pnae-sobre-o-pnae. Acesso em: 26 dez. 2018b. 
GODOY, A. S. O estudo de caso qualitativo. In: GODOI, C. K.; BANDEIRA-DE-MELLO, R.; SILVA, A. B. (org.). Pesquisa qualitativa em estudos organizacionais: paradigmas, estratégias e métodos. 2. ed. São Paulo: Saraiva, 2010.

IFAD. International Fund for Agricultural Development. Smallholders, food security and the environment. United Nations Environment Program, 2013. Disponível em: https://www.ifad.org/documents/38714170/39135645/smallholders_report.pdf/133e8903-0204-4e7d-a780-bca847933f2e. Acesso em: 10 jun. 2019.

LATOUR, B.; WOOLGAR, S. A vida de laboratório: a produção dos fatos científicos. Rio de Janeiro: Relume Dumará, 1997.

LATOUR, B. A esperança de Pandora: ensaios sobre a realidade dos estudos científicos Filosofia e política. Bauru: Editora da Universidade do Sagrado Coração; Edusc, 2001.

LATOUR, B. Reagregando o social: uma introdução à teoria do ator-rede. Salvador: Edufba, 2012.

LAW, J. Notes on the theory of the actor-network: ordering, strategy and heterogeneity. Systems Practice, v. 5, n. 4, p. 379-393, 1992. Disponível em: https://www.researchgate.net/publication/226153573_notes_on_the_theory_of_the_actor-network_ordering_strategy_and_heterogeneity. Acesso em: 10 jun. 2019.

LÉLÉ, S. M. Sustainable development: a critical review. World development, v. 19, n. 6, p. 607-621, 1991. Disponível em: https://pdfs.semanticscholar.org/4aae/8fff2a027efe8a543c76e4eee963122635e6.pdf. Acesso em: 10 jun. 2019.

MALUF, R. S. J. Mercados agroalimentares e a agricultura familiar no Brasil: agregação de valor, cadeias integradas e circuitos regionais. Ensaios FEE, Porto Alegre, v. 25, n. 1, p. 299-322, 2004. Disponível em: https://revistas.fee.tche.br/index.php/ensaios/article/viewFile/2061/2443. Acesso em: 10 jun. 2019.

MERRIAM, S. B. Introduction to qualitative research. Qualitative research in practice: examples for discussion and analysis. [S.I.]: [s.n.], 2002.

MORAES, M. A ciência como rede de atores: ressonâncias filosóficas. História, Ciências, Saúde - Manguinhos, v. 11, n. 2, p. 321-323, 2004. Disponível em: http://www.scielo.br/scielo.php?pid=S0104-59702004000200006\&script=sci_abstract\&tlng=pt. Acesso em: 10 jun. 2019.

MORIN, E. A cabeça bem-feita: pensar a reforma, reformar o pensamento. Rio de Janeiro: Bertrand Brasil, 2002.

NAVARRO, Z. A agricultura familiar no Brasil: entre a política e as transformações da vida econômica. In: GASQUES, J. G.; VIEIRA FILHO, J. E. R.; NAVARRO, Z. (org.). A agricultura brasileira: desempenho, desafios e perspectivas. Brasília: Ipea, 2010. p. 185-209.

OERLEMANS, N.; ASSOULINE, G. Enhancing farmers' networking strategies for sustainable development. Journal of Cleaner Production, 12, p. 469-478, 2004.

ONU. Organização das Nações Unidas. United Nations. 17 Goals to Transform Our World, 2019. Disponível em: un.org/sustainabledevelopment. Acesso em: 10 jun. 2019.

PECI, A.; ALCADIPANI, R. Demarcação científica: uma reflexão crítica. Organizações \& Sociedade, v. 13, n. 36, p. 145-161, 2006. Disponível em: https://portalseer.ufba.br/index.php/revistaoes/article/view/10827. Acesso em: 10 jun. 2019.

RONDÔNOA. Empresa de Assistência Técnica e Extensão Rural do Estado de Rondônia (Emater-RO). Desenvolvimento social, 2019a. Disponível em: http://www.emater.ro.gov.br/ematerro/desenvolvimento-social/. Acesso em: 10 jun. 2019.

RONDÔNOA. Empresa de Assistência Técnica e Extensão Rural do Estado de Rondônia (Emater-RO). Entrevista 2. Entrevistador: Eliane Alves da Silva. maio 2019b. 1 arquivo .mp3 $40 \mathrm{~min}$.

SACHS, I. Qual desenvolvimento para o século XXI? In: BARRÈRE, M.; ABREU, E. D. S. (ed.). Terra, patrimônio comum: a ciência a serviço do meio ambiente e do desenvolvimento. São Paulo: Nobel, 1992.

SAUNDERS, M.; LEWIS, P.; THORNHILL, A. Research Methods for Business Students. 6. ed. Essex, England: Pearson, 2012.

SCHERMER, M. From "Food from Nowhere" to "Food from Here:" changing producer-consumer relations in Austria. Agriculture and Human Values, n. 32, p. 121-132, 2015. Disponível em: http://ambiental.adv. br/ufvjm/ea2012-1sachs.pdf. Acesso em: 10 jun. 2019.

SCHWARTZMAN, F.; MORA, C. A. R.; BOGUS, C. M.; VILLAR, B. S. Antecedentes e elementos de vinculação do Programa de Alimentação Escolar do Brasil com a Agricultura Familiar. Cadernos de Saúde Pública, v. 33, n. 12, 2017. Disponível em: http://www.scielo.br/scielo.php?pid=S0102-311X2017001200501\&script=sci_abstract\&tlng=pt. Acesso em: 10 jun. 2019.

SEMED. Secretaria Municipal de Educação. Entrevista 1. Entrevistador: Eliane Alves da Silva. maio 2019. 1 arquivo .mp3 (60 $\mathrm{min}$.). 
SILVA, C. E. M. Modo de apropriação da natureza e territorialidade camponesa: revisitando e ressignificando o conceito de campesinato. Geografias. Belo Horizonte, v. 3, n. 1, p. 46-63, 2007. Disponível em: https://periodicos.ufmg.brindex.phpıgeografiasıarticlesdownload. Acesso em: 20 dez. 2019.

STAKE, R. E. Case Studies. In: DENZIN, N. K. L., Y. S (ed.). Handbook of Qualitative Research. 2. ed. London: Sage Publications, 2000.

TONELLI, D. F. Epistemological origins and affiliations of the Actor-Network Theory: implications for organizational analysis. Cadernos EBAPE.BR, v. 14, n. 2, p. 377-390, 2016. Disponível em: http://www.scielo. br/scielo.php?script=sci_arttext\&pid=S1679-39512016000200377. Acesso em: 10 jun. 2019.

UNICAFES. União das Cooperativas da Agricultura Familiar e Economia Solidária. Documento Base V Congresso, Brasília, 2017. Disponível em: http://unicafes.org.br. Acesso em: 10 jun. 2019.

VILAS-BOAS, L. G. Palavras e expressões ideológicas sobre a questão agrária. Caminhos de Geografia, v. 19, n. 66, 2018. Disponível em: http://www.seer.ufu.br/index.php/caminhosdegeografia/article/view/35795. Acesso em: 20 dez. 2019.

YIN, R. Estudo de caso: planejamento e métodos. 2. ed. Porto Alegre: Bookman, 2001.

ZANCO, A. M.; CORBARI, F.; ALVES, A. F. Conexão entre as teorias de redes e as redes solidárias. Revista GeoPantanal, v. 24, p. 233-250, 2018. Disponível em: http://desafioonline.ufms.br/index.php/revgeo/article/view/6316/4965. Acesso em: 10 jun. 2019.

ZOCCHIO, G. MPF diz que extinção do CONSEA é inconstitucional e pede ação no Supremo, 2019. Disponível em: https://outraspalavras.net/ojoioeotrigo/2019/02/mpf-diz-que-extincao-do-consea-e-inconstitucional-e-pede-acao-no-supremo/. Acesso em: 10 jun. 2019. 